\title{
Servanne Jollivet, L'Historisme en question. Généalogie, débats et réception (1800-1930)
}

\section{Sylvain Ledda}

\section{(2) OpenEdition}

1 Journals

\section{Edizione digitale}

URL: http://journals.openedition.org/studifrancesi/5348

DOI: 10.4000/studifrancesi.5348

ISSN: 2421-5856

\section{Editore}

Rosenberg \& Sellier

\section{Edizione cartacea}

Data di pubblicazione: 1 dicembre 2016

Paginazione: 533

ISSN: 0039-2944

\section{Notizia bibliografica digitale}

Sylvain Ledda, «Servanne Jollivet, L'Historisme en question. Généalogie, débats et réception (1800-1930) », Studi Francesi [Online], 180 (LX | III) | 2016, online dal 01 janvier 2017, consultato il 18 septembre 2020. URL : http://journals.openedition.org/studifrancesi/5348 ; DOI : https://doi.org/10.4000/ studifrancesi.5348

Questo documento è stato generato automaticamente il 18 settembre 2020.

\section{(c)}

Studi Francesi è distribuita con Licenza Creative Commons Attribuzione - Non commerciale - Non opere derivate 4.0 Internazionale. 


\title{
Servanne Jollivet, L'Historisme en question. Généalogie, débats et réception (1800-1930)
}

\author{
Sylvain Ledda
}

\section{NOTIZIA}

SERVANNE JOLLIVET, L'Historisme en question. Généalogie, débats et réception (1800-1930), Paris, Honoré Champion, 2013, «Travaux de philosophie», 440 pp.

1 Né aux premières lueurs du $\mathrm{XIX}^{\mathrm{e}}$ siècle, le concept d'historisme constitue une voie d'accès à la compréhension des phénomènes sociétaux contemporains. Dans son ouvrage, Servanne Jollivet pose clairement les enjeux de cette notion «équivoque» (p.13) issue de la philosophie allemande. Objet de nombreux débats, l'historisme est une notion qui questionne en effet «la fin de l'histoire» (p. 405). Comme le note d'emblée la critique, l'historisme (traduit de l'allemand Historizmus) «soutient une véritable offensive idéologique ou au contraire attaque polémique». L'historisme est donc un concept né des révolutions, qui invite à repenser l'histoire non plus en termes universalistes mais en prenant acte des crises sur l'évolution des nations. L'enquête de Servanne Jollivet est a priori diachronique, mais pas seulement. La notion d'historisme est en effet analysée en fonction de grandes scansions de l'histoire qui sont aussi celles de la pensée européenne, à travers le prisme de la philosophie allemande (Kant et les néokantiens, Nietzsche, Heidegger). Constamment nourrie d'une très solide connaissance des textes, des concepts, l'étude se fixe comme dessein de définir la notion dans le champ culturel du XIX ${ }^{\mathrm{e}}$ siècle (principalement) et du début du $\mathrm{Xx}^{\mathrm{e}}$ siècle. Après avoir établi un état des lieux de la recherche, l'ouvrage cherche à réhabiliter la notion d'historisme à l'intérieur du paysage philosophique contemporain pour mieux montrer son impact dans les sciences humaines en général. Né avec Schlegel et Novalis, l'historisme sera finalement fortement remis en cause quand émerge le nationalsocialisme des années 1930. Ainsi fixées, les bornes chronologiques de l'étude signalent 
l'ampleur d'une enquête menée avec rigueur et finesse. L'ancrage initial dans la philosophie allemande de la fin du XIx ${ }^{e}$ siècle évolue vers une double acception de la notion, suscitant une radicalisation ou une relativisation de celle-ci. Enfin, la troisième partie de l'ouvrage, particulièrement réussie, analyse «la crise de l'historisme» qui émerge au début $\mathrm{du} \mathrm{xx}^{\mathrm{e}}$ siècle. En traversant ainsi plus de cent ans d'histoire de la pensée européenne, Servanne Jollivet apporte une meilleure connaissance des sciences humaines en général; sur le plan de la méthode épistémologique, elle démontre aussi que l'engagement philosophique, quand il convoque les autres disciplines (histoire, sociologie, anthropologie), gagne en pertinence. Ajoutons enfin que cet ouvrage remarquable est doté d'un précieux index et écrit dans une langue claire. Il s'adresse à un lectorat averti. 